\title{
Organización y programa político de los "gauchos" de Jujuy a fines de la Guerra de Independencia*
}

\section{GABRIELA GrESORES}

Afiliada institucionalmente a la Facultad de Humanidades y Ciencias Sociales Universidad Nacional de Jujuy (Argentina).Correo electrónico: gabrielagresores@gmail.com. La autora es Magister en Historia Americana de la Universidad Internacional de Andalucía (España). Entre sus publicaciones recientes tenemos: en coautoría "“un servicio humanitario". La circulación de mano de obra compulsiva en el trabajo agrario a principios del siglo XX", Revista Nuestro NOA, No. 11 (2017). Entre sus temas de interés se encuentran Historia Social de la Guerra de Independencia y Población indígena y trabajo compulsivo.

Recibido: 15 de abril de 2019

Aprobado: 10 de noviembre de 2019

Modificado: 20 de noviembre de 2019

Artículo de investigación científica

DOI: http://dx.doi.org/10.15648/hc.36.2020.5

Este artículo forma parte de los proyectos "Programa Universitario de Historia Argentina" y "Espacios rurales de Jujuy y mercados de trabajo extralocales" financiados por Ministerio de Educación Ciencia y Tecnología de la Nación. Secretaría de Políticas Universitarias (Argentina) y de la Secretaría de Ciencia y Tecnología Universidad Nacional de Jujuy (Argentina).

Esta publicación está bajo una licencia Creative Commons Reconocimiento-NoComercial 4.0 
Organización y programa político de los "gauchos" de Jujuy a fines de la Guerra de Independencia

\section{Resumen}

Este artículo utiliza la información sobre un motín de "escuadrones gauchos" en el norte de la actual provincia de Jujuy, una región que en ese preciso momento se está construyendo como frontera entre Bolivia y Argentina, para establecer elementos de la politización de los sectores populares en la Guerra de Independencia: construcciones identitarias, objetivos, formas discursivas, principios organizadores, etc. El trabajo se basa sobre análisis del discurso y del contenido de repertorio de fuentes diversas: sumarias militares, informes, correspondencia personal y militar, originadas en la represión del conflicto.

Palabras clave: Guerra de Independencia, Milicias, Gauchos, politización popular, Jujuy.

Organization and political program of the "gauchos" of Jujuy at the end of the War of Independence

\section{Abstract}

This article uses information about a riot of "gaucho squads" in the north of the current province of Jujuy, a region which at that precise moment is being built as a border between Bolivia and Argentina. The purpose was to establish elements of the politicization of the popular sectors in the Independence War: identity constructions, objectives, discursive forms, organizing principles, etc. The work is based on analysis of discourses and the content of diverse sources repertoire: military summaries, reports, personal and military mail originated in the repression of the conflict.

Key words: War of Independence, Militias, Gauchos, popular politicization, Jujuy.

Organização e programa político dos "gaúchos” de Jujuy no final da Guerra da Independência

\section{Resumo}

Este artigo utiliza informações sobre um motim de "esquadrões gaúchos" no Norte da atual província de Jujuy, região que naquela época estava sendo construída como 
fronteira entre a Bolívia e a Argentina, para estabelecer elementos de politização dos setores populares. Na Guerra da Independência: construções de identidades, objetivos, formas discursivas, princípios organizadores, etc. $\mathrm{O}$ trabalho baseia-se na análise do discurso e do conteúdo do repertório de diversas fontes: resumos militares, relatórios, correspondência pessoal e militar, originadas na repressão do conflito.

Palavras-chave: Guerra da Independência, Milícias, Gaúchos, Politização popular, Jujuy.

Organisation et programme politique des «gauchos» de Jujuy á la fin de la Guerre d'Indépendance

\section{Résumé}

Cet article utilise l'information sur une révolte de «escuadrones gauchos» au nord de celle qui est actuellement la province de Jujuy, une région qu' à ce moment- là était en train de devenir la frontière entre la Bolivie et l'Argentine, pour établir des éléments dans la conscience politique des secteurs populaires pendant la Guerre d'Indépendance: des constructions identitaires, objectifs, formes discursives, principes d'organisation, etc. Le travail est basé sur l'analyse du discours et du contenu du répertoire de différentes sources: Résumés des procès militaires, rapports, correspondance personnelle et militaire, nées de la répression du conflit.

Mots clés: Guerre d’indépendance, milices, Gauchos, politisation populaire, Jujuy.

\section{INTRODUCCIÓN}

Decían las abuelas que no se encuentran cosas nuevas haciendo siempre lo mismo. Y es así que curioseando papeles más allá de los límites de la Guerra de Independencia -objeto de nuestros desvelos de los últimos años- nos topamos con una historia de rebeldía que en principio pareció nimia, pero que al tirar del ovillo, empezó a mostrar múltiples dimensiones y una riqueza inusitada, de la cual este artículo es sólo una muestra que nos permite instalarnos en un terreno particularmente delicado, como lo es el de las intervenciones políticas de los sujetos sub- 
alternos ${ }^{1}$. Decimos delicado ya que hablar de intervención es hablar de su construcción como sujetos políticos y nos obliga a interrogar viejos mitos y nuevas mistificaciones. Si esto ha sido soslayado por las sucesivas historiografías oficiales, la exaltación del frenesí conmemorativo de los bicentenarios, a la par que legítimas demandas populares por la Historia, han permitido la emergencia de las voces subalternas, dando lugar a avances y retrocesos en cuanto a la apropiación popular de la historia de interesante pronóstico.

Traduciendo estas generalidades, en Jujuy, hablar de los protagonistas de la Independencia hoy, es interpelar a un conjunto de sensibilidades muy activas, frente a quienes nos sentimos comprometidos, pero a quienes no estamos seguros de complacer, a causa de las trasposiciones sucesivas que ha sufrido el imaginario sobre los gauchos en la Argentina en general, y en Salta y Jujuy en particular.

Dos elementos de partida a remarcar: el primero es que acción revolucionaria y guerra, en diferentes proporciones, hicieron trizas de conjunto el orden social colonial, este relato se vincula entonces, con proyectos alternativos al ordenamiento que se estaba creando sobre las cenizas del régimen destrozado. Vinculado con este elemento, y en polémica con los aquellos que entienden a los sujetos subalternos como un telón de fondo donde los dirigentes bordan sus acciones heroicas o desafortunadas, el conflicto que analizaremos nos permite apreciar la profundidad y amplitud de los procesos de politización de las clases populares rurales jujeñas.

1 Las intervenciones de los subalternos en la política revolucionaria han concitado mucho interés entre los investigadores y ha generado una profusa producción con proyecciones más que promisorias. Para no sobreabundar en la bibliografía sólo citaremos parte de la bibliografía más reciente sobre los "gauchos de Güemes". Sara E. Mata, Los gauchos de Güemes. Guerras de Independencia y conflicto social (Buenos Aires: Sudamericana, 2008); Viviana Conti “Jujuy 1810", en Jujuy de la Revolución de Mayo a nuestros días, eds. Marcelo Lagos y Viviana Conti (San Salvador de Jujuy: Ediunju, 2010). Gustavo Paz Province and Nation in Northern Argentina. Peasants, Elite, and the State, 1780-1880, tesis de doctorado en Historia, Universidad Emory, 1999); Raquel Gil Montero, "Las Guerras de Independencia en los Andes Meridionales", Memoria Americana 14 (2006). Entre muchos otros. 
Estamos lejos todavía del conocimiento que se tiene sobre la insurrección agraria salteña ${ }^{2}$. Su estudio permitió poner a foco un sujeto social hasta ese momento menos conocido que glorificado: conocido precisamente por su nombre mítico como "los gauchos de Güemes". A diferencia de los gauchos rioplatenses, personajes de mala fama, dentro de la vida agraria colonial, frecuentemente asociados con una vida libre y la vagancia, el vocablo gaucho no se utilizaba en Salta y Jujuy hasta la guerra.

Es en el trance bélico -y según hemos podido constatar, claramente a principios de 1814- que José de San Martín - a la sazón Comandante del Ejército Auxiliar del Perú, con asiento en Tucumán, y a punto de renunciar- y otros dirigentes -posiblemente a instancias de Güemes- comienza a escribir insistentemente en sus informes la palabra "gaucho" para designar a los miembros de las partidas de voluntarios reclutados en el ámbito rural.

A pesar de que en los documentos el término aparece asociado a elogios, fue notoriamente resistido por la dirigencia política en Buenos Aires, ya que en las transcripciones oficiales aparece sistemáticamente tachado y reemplazado por "paisano"3 "campesino", y "patriota"

A los pocos meses, la palabra gaucho había pasado de designar al "paisanaje inerme" que acompañaba al ejército, al conjunto de las milicias de Salta y Jujuy, organizadas en "escuadrones gauchos”. Se garantizó así, para sus integrantes, condiciones que éstos ya habían comenzado a implementar -de hecho- a partir de la crisis del orden colonial: la eximición del pago de arrendamientos y la tolerancia a la desobediencia a sus patrones a través del "fuero militar", que los ponía bajo la protección

2 Sara E. Mata, “Tierra y revolución. La campaña salteña en las primeras décadas del siglo XIX” Mundo Agrario Vol. 17 No. 35 (2016).

3 "Oficio de San Martín al Director" (Tucumán, 1 de abril de 1814), Archivo General de la Nación (AGN), Sala X 7-3-10 Doc. 89.

4 "Parte de Güemes a San Martín" (29 de marzo de 1814), AGN, Sala X 7-3-10. Doc. 89.

5 "Oficio de San Martín al Director" (23 de marzo de 1814), AGN, Sala X 7-3-10. Doc.79.

6 "Oficio de José Apolinar Saravia a San Martín", AGN, Sala X 7-3-10. 
de su principal líder y jefe militar, Martín Miguel de Güemes, o los jefes intermedios ${ }^{7}$.

Diez años más tarde, aún varios años después de la muerte de Güemes, acaecida en 1821, el sistema había mantenido sus principios fundacionales, y se había consolidado. A pesar de las protestas de patronos y funcionarios, a pesar de las limitaciones que se intentaban introducir a través de múltiples legislaciones ${ }^{8}$, el presente trabajo se suma a aquellos que postulan para Salta, cierto éxito en mantener las prerrogativas gauchas hasta fines de la década de 1820- y en la persistencia de una crisis radical en las relaciones entre la plebe rural y los sectores dominantes, eventualmente tolerada por la eficacia que los gauchos habían demostrado una y otra vez, en la lucha contra los realistas y por la pertinaz resistencia de los guerreros a resignar sus principios ${ }^{9}$. De eso se trata nuestra historia.

\section{La tropa del escuadrón de gauchos de Caspalá}

Aunque no ha sido sistematizado aún, pueden advertirse diferencias sociales y organizativas entre los integrantes de los escuadrones gauchos de Salta y Jujuy y de las diferentes regiones de Jujuy entre sí. No hablaremos entonces de un motín "gaucho" en general, sino de un motín de los gauchos del Zenta y Valle Grande, y esta especificidad no es un dato más, sino una de las claves explicativas de la problemática histórica que queremos desarrollar.

Para describir el escenario de nuestro drama, es necesario destacar que las regiones de Valle Grande, Santa Victoria y el Zenta ocupan una fran-

7 Sara E. Mata, "Conflicto y violencia en tiempos de crisis. Salta (Argentina) en las primeras décadas del siglo XIX”, Revista Secuencia 90 (2014): 2.

8 Gustavo Paz "Reordenando la campaña: la restauración del orden en Salta y Jujuy, 1822-1825”, en ¿Y el pueblo dónde está? Contribuciones para una historia popular de la Revolución de Independencia en el Río de la Plata, ed. Raúl Fradkin (Buenos Aires: Prometeo. 2015), 194.

9 Sara Mata, Conflicto político y propiedad de la tierra. Salta 1810-1830, VIII Jornadas Interdisciplinarias de Estudios Agrarios y Agroindustriales (Buenos Aires: Centro Interdisciplinario de Estudios Agrarios, 2013)

http://www.ciea.com.ar/jornadas-anteriores/viii-jornadas-interdisciplinarias-de-estudios-agrarios-y-agroindustriales-2013/12/4/2019 
ja que se extiende de sur a norte por la zona oriental de la provincia de Jujuy y una pequeña parte de Salta, limitando con la llanura chaqueña. Era, en el siglo XIX y sigue siendo, un conjunto de parajes abruptos, aislados e inaccesibles, breves espacios que pasan de la aridez de la Puna a la humedad de la selva de montaña; de los 3.800 a los 400 metros sobre el nivel del mar; peñas y abismos, quebradas profundas, caminos de herradura, en el mejor de los casos.

Las dificultades de acceso -entre otros elementos- moldearon la integración estos valles como una periferia de las principales vías de comunicación y comercio; con una producción de autoconsumo, básicamente ganadera ${ }^{10}$. Las tierras se habían repartido como mercedes, en expansiones más bien tardías, pero justamente sus desventajas y por ende, la baja densidad de población, las hacían poco apetecibles ${ }^{11}$.

Podríamos decir que para asentarse en esa región, sus pobladores partieron de una decisión política: abandonar las ventajas de una vida social integrada a cambio de cuotas mayores de autonomía personal y grupal; y desarrollaron una gran adaptación al medio pagando altos costos para el desarrollo de su vida social, cultural y económica, esfuerzos que esperaban recompensas.

El conflicto se inicia con la negativa de los integrantes de un escuadrón gaucho de Caspalá a cumplir la orden de dejar el aislamiento de su localidad; ellos sienten esta orden como una amenaza a su integridad y libertad. Sin embargo, este hecho inorgánico, defensivo y hasta aparentemente pueril, no se resuelve mediante los mecanismos habituales de

10 Juan Pablo Ferreiro y Federico Fernández "Vino nuevo en viejos odres. Perspectiva microestructural, redes y fuentes tradicionales”, Econtros Bibli Vol. 19 (2014): 157-184 http://hdl.handle. net/11336/36201; Ana Teruel y Omar Jerez comps, Pasado y presente de un mundo postergado. San Salvador de Jujuy: Unidad de Investigación en Historia Regional-UNJu (1998).

11 Gabriela Sica, "Paisajes agrarios coloniales en la Quebrada de Humahuaca. Tierras privadas, tierras comunales. Siglos XVI-XVIII”, en Quebrada de Humahuaca. Estudios Históricos y Antropológicos en torno a las formas de propiedad, eds. Ana Teruel y Cecilia Fandos, (San Salvador de Jujuy: Ediunju. 2014); Raquel Gil Montero, La construcción de Argentina y Bolivia en los Andes Meridionales. Población, tierras y ambiente en el siglo XIX (Buenos Aires: Prometeo, 2008); Elena Belli “Algunas implicancias de las políticas de ajuste económico y modernización en Valle Grande Provincia de Jujuy" (tesis doctorado en Antropología, Universidad de Buenos Aires, 2004) URI: http://repositorio. filo.uba.ar/handle/filodigital/1253 
disuasión o represión y pasados los meses se convierte en una rebelión de fuste, con programas, caudillos, proclamas, alianzas interregionales. Así se transforma y confluye en un conflicto generalizado, que amenaza la frontera entre la nueva República de Bolivia y Jujuy; y que prolonga sus estertores sin terminar de resolverse hasta promediar el siglo XIX.

De resistencia casi cotidiana a utopía libertaria. Como trasfondo, y despuntando sólo a través de ciertos indicios, está la pertenencia étnica de estos sujetos.

Es conocida la participación de diferentes grupos indios en las guerras de independencia, y su integración en los escuadrones gauchos. Sin embargo, en el imaginario popular, gauchos e indios son dos sujetos diferentes y frecuentemente opuestos.

No analizaremos aquí los fundamentos de estas ideas tan enraizadas en las construcciones identitarias provinciales. Simplemente señalaremos que en los documentos que relatan el conflicto que estamos analizando, hay indicios fuertes de que estos escuadrones de Caspalá, Iruya y Valle Grande están compuestos mayoritariamente por indios ${ }^{12}$. La constatación de esta hipótesis, pero sobre todo la indagación de modalidades y significaciones será puesto a foco en próximos trabajos

Debemos aclarar que este es el primer trabajo que realizamos sobre la temática y una primera indagación sobre un conjunto acotado de fuentes, seleccionado de un corpus muy nutrido y que reúne -afortunadamente para nuestra investigación- documentos de muy diversa índole. En particular quiero destacar la presencia de algunas cartas aparentemente escritas de puño y letra de los protagonistas. Es conocido el tópico historiográfico de la dificultad del estudio de los sectores subalternos, ya que sus voces no suelen aparecer de primera mano. Por el contrario, la existencia de estas cartas nos permiten estudiar de primera mano estas voces, las cuales nos llevan a interrogaciones de lo más variadas, incluso

12 1826, Archivo Histórico de la Provincia de Jujuy (AHPJ), Gobierno, Fondo Archivo, caja 2. 
lingüísticas y psicológicas; pero en particular la pregunta de quién había enseñado a escribir a esta población rural ${ }^{13}$.

Este trabajo inicial nos permite postular que esta reacción del escuadrón gaucho, parecería indicar la existencia de una conflictividad poliforme, que la finalización de la guerra y su articulación con los procesos de organización/desorganización del espacio sociopolítico a escala del antiguo virreinato, no hacen más que multiplicar como un efecto de billar, en donde la dispersión del golpe mueve elementos muy periféricos, a los cuales termina otorgándoles centralidad.

\section{Los gaUchos DICEN QUE NO SALEN}

El día 31 de Agosto de 1826 los oficiales del Escuadrón de Gauchos de Caspalá intentan reunir la tropa para cumplir la orden de su comandante, José Francisco Pastor -con asiento en Humahuaca- para que se marchen hacia aquella localidad para -según se les informará más tarde- escoltar a unos reclutas provenientes de Tarija hasta Tilcara. Los soldados se presentan ante la convocatoria de sus oficiales de a pie, sin sus caballos:

“... en una voz tumultuosa diciendo que no podían salir a parte alguna... que sabían posiblemente que en el momento de salir de sus casas los habrían de reclutar y que por este temor no querían salir del Valle... que nadie los había dicho pero que ellos lo sabían"14.

En los testimonios que recogerá la sumaria investigación que se desarrolla a continuación, los interrogados repetirán con leves diferencias esta versión local de la respuesta a lo Fuenteovejuna, en donde el colectivo se muestra con una cohesión tal, que responde como un sujeto único de la acción. El relato de la jornada se reitera una y otra vez, mien-

13 Agradezco a José Carlos Chiaramonte el comentario más que pertinente de que "quien enseña a escribir, enseña principalmente ideas". Para épocas tan tempranas, hemos encontrado para la misma época, conflictos con maestros de primeras letras -laicos- en Caspalá y en Tilcara. Tema sobre el que no hemos encontrado estudios hasta el momento y que también deberán profundizarse en un futuro. 1826, AHPJ, Gobierno, Fondo Archivo, caja 2. 
tras que los oficiales se lamentan de que sus esfuerzos por persuadir a la tropa no hayan tenido frutos.

Este episodio nos permitió reflexionar hasta qué punto la exención de la leva y el servicio en el propio territorio era la tercera pata -junto con la suspensión del pago de arrendamientos y el fuero - sobre la que se apoyaba la adhesión de la población rural al "sistema" de Güemes, aún después de su muerte. Es más, la propia situación que estamos relatando, sumada a algunos otros indicios nos inducen a preguntarnos si esta pata implícita no habrá sido, al menos en algunas regiones, el impulso principal de la adhesión de la población frente a los otros.

Detengámonos en este asunto de central importancia para la definición más precisa de nuestros sujetos. Avanzado el conflicto, Mauricio de Goyechea, miembro de la familia beneficiaria de tierras de Valle Grande, por merced real ${ }^{15}$, viaja hasta Caspalá para cobrar los arrendamientos que le corresponden. Independientemente del resultado obtenido en ese momento, sobre lo que volveremos oportunamente, lo interesante es que no parece ser una situación excepcional ni conflictiva; todo indica que los gauchos de Caspalá continuaban pagando sus arriendos ${ }^{16}$.

¿Estaba vigente aún en 1826 la exención del pago de arrendamiento para los gauchos? No sin conflicto, hemos podido rastrear la vigencia legal de dicha prerrogativa hasta 1828, por lo menos, si bien las reiteradas aclaraciones del gobierno en este sentido, nos dan a entender de que el cobro de arrendamientos no era tan extraño ${ }^{17}$.

Por otra parte, resulta interesante observar que las quejas y conflictos más frecuentes entre patronos y trabajadores estaba centrado más en la escasez de peones, los problemas de disciplina y en particular la disputa por el acceso al ganado ${ }^{18}$. No quiero decir con esto que la exención del

15 Gabriela Sica, "Paisajes agrarios coloniales en la Quebrada de Humahuaca. Tierras privadas, tierras comunales. Siglos XVI-XVIII”, en Quebrada de Humahuaca. Estudios Históricos y Antropológicos en torno a las formas de propiedad, eds. Ana Teruel y Cecilia Fandos, (San Salvador de Jujuy: Ediunju. 2014). 52

16 1826, AHPJ, Gobierno, Fondo Archivo, caja 2.

171823,1824 y 1828, AHPJ, Fondo Archivo.

18 Gustavo Paz, "El orden es el desorden” Guerra y movilización campesina en la campaña de Jujuy, 
arrendamiento no fue un aliciente poderoso, sino que quizá no fue el principal ocasionalmente para todos.

Sabemos que la incorporación a los escuadrones "gauchos" implicó de por sí un escudo importante contra las permanentes levas que sufrían los sectores populares. El mismo Güemes experimentó los alcances y los límites que imponía la movilización campesina y en particular en Jujuy, en donde cada escuadrón tenía la oportunidad -más frecuente que en Salta- de pelear en su propio territorio, casi podríamos decir su propia casa ${ }^{19}$.

A pesar de que iba de suyo que la pertenencia a los escuadrones gauchos era reclutamiento, Güemes entendió necesario solicitar y obtener del Director Pueyrredón que se pronuncie sobre la eximición de levas para los milicianos:

"se digne prestar su superior declaración, para que en ningún tiempo se me arguya falta de cumplimiento. Vuestra excelencia es un testigo ocular, que todos los hombres que podían destinarse al ejército, están siempre ocupados en el servicio de la causa pública... a primera vista se descubre que toda la provincia en masa, repele, rechaza y contiene a aquellos". Y no evitará su acostumbrado ademán paternalista al solicitar que no se realicen levas: "A vista pues de tan poderosos fundamentos nada tiene de extraña mi protección hacia estos infelices...tengo el honor de impetrar y exigir la gracia de que por ahora sea esta benemérita provincia excenta de la obligación que la sujeta la citada orden del 24 de agosto..."20.

1815-1821”, en Desafíos al Orden. Política y sociedades rurales durante la Revolución de Independencia, comp. Raúl Fradkin y Jorge Gelman (Rosario: Prohistoria, 2008).

19 En este caso, el Zenta y Valle Grande constituyeron un camino secundario pero frecuente de avance de las tropas realistas. Coronel Emilio A. Bidondo. Contribución al Estudio de la Guerra de la Independencia en la Frontera Norte. El Aporte Jujeño. (Buenos Aires: Círculo Militar, 1968) Anexo 7, $7^{\mathrm{a}}$, $7 \underline{\mathrm{b}}, 10,11,12^{\mathrm{a}}, 17,18,19$.

20 "Oficio de Güemes al Director Pueyrredón (Salta, 17 de octubre de 1816)", en Güemes documentado, ed. Luis Güemes (Buenos Aries: Editorial Plus Ultras, 1979), Tomo 4, 69-70. 
Pero en Caspalá, en 1826 ¿Qué elementos tenían los gauchos para alimentar sus sospechas? En principio su propia experiencia. Avanzado el conflicto, y continuados los interrogatorios los gauchos declaraban:

"que los temores que les acompañaban a todos era el que los reclutasen para las tropas y que era fundado porque en dos ocasiones ha sucedido que con pretexto de ordenes nos han hecho bajar y han sido en la primera reclutados cinco por el Coronel Don Francisco Pastor y la segunda vez cuatro por el mismo señor..."21.

Afortunadamente contamos con documentación para establecer la veracidad de algunos de los argumentos presentados en el momento y ampliar la mira hacia una problemática mayor. Por una parte, sería cierto el argumento del Comandante Pastor, acerca de que la convocatoria estaba dirigida a escoltar a reclutas de Tarija.

Este tema de los reclutas de Tarija es el primero, pero no el único ni el principal eslabón que enlazará nuestra historia con la problemática tarijeña. Es precisamente en ese momento en que las fuerzas políticas están dirimiendo la pertenencia de dicho territorio a una unidad mayor.

Este debate que se dirimió bajo la presión de levantamientos y sublevaciones, se presentaba bajo tres opciones: la continuidad de Tarija como parte de la Provincia de Salta, la integración como provincia dentro de una Argentina -que tendrá para ese momento la efímera existencia republicana de Rivadavia- o integrarse a la República de Bolivia, que acababa de constituirse.

Como parte de los esfuerzos para que permanezca bajo el control salteño, Alvarez de Arenales -quien por entonces era gobernador de Salta, pero también un líder de consenso en el Alto Perú- se encontraba en Tarija tratando de imponer acciones de enlace con la provincia y el gobierno nacional. En este contexto es que el Congreso General de 84 las Provincias Unidas del Río de la Plata ordena que Tarija separe de

21 1826, AHPJ, Gobierno, Fondo Archivo, caja 2. 
sus escuadrones de milicias, 200 reclutas para formar parte del Ejército Nacional que por entonces se estaba formando,

"que al mismo tiempo que mantenga ilesos los sagrados derechos de la Independencia sellada con torrentes de Sangre Americana, conserve igualmente la integridad del territorio Argentino". Dichos reclutas "que deberán ser precisamente jóvenes de catorce a veinte años; de familias a quienes hagan menos falta, pero no vagos, ni viciosos, ni lexionados" deberían marchar hacia Salta bajo el mando del Coronel Comandante Don Eustaquio Mendez..."22.

Suponemos que demorados por la conflictiva situación tarijeña, y sin el jefe asignado -el cual se encuentra en ese momento encabezando una rebelión- son esos reclutas los que se ordena que deben ser escoltados desde Humahuaca a Tilcara, detonando una situación que seguramente se había ido armando involuntariamente con la sumatoria de las reiteradas injurias. La imponente custodia que debía organizarse da muestra de lo violento de la situación: “que se apresten 100 hombres armados para la escolta...y de que se cubran los caminos estrabiados y retaguardia con la jente restante de este partido..." 23 .

Pero, por su parte, la resistencia gaucha tenía también suficientes motivos: diversos documentos nos hablan de reiterados intentos de reclutamientos forzosos que violaban los acuerdos para que los milicianos no fueran molestados en su servicio en su territorio. Contrariando prerrogativas de las tropas milicianas, las levas habían recrudecido, y apuntaban a reclutar a dichas tropas por tratarse de veteranos.

A modo de ejemplo, señalamos que, a pesar de las conocidas reticencias que relata José María Paz, en cuanto a los gauchos, estos componían su hueste, con la que enfrentó a Olañeta en 1825, en los últimos combates altoperuanos. Con estos mismos hombres, dice Paz den sus memorias,

22 "Disposición del Congreso General de las Provincias Unidas del Río de la Plata (Buenos Aires, 13 de septiembre de 1825)" en Historia de Tarija, dir. Cristina Minutolo de Orsi (Corpus Documental) (Tarija: Universidad Autónoma "Juan Misael Saracho", 1987), Tomo III, 187-189.

"Oficio de Juan Francisco Pastor”, 1826, AHPJ, Fondo Archivo. 
“...se armó el contingente de la misma provincia para el ejército nacional que se organizaba en la Banda Oriental para la guerra del Brasil. Con ella salí el 2 de Diciembre del mismo año, atravesando 400 leguas para tomar parte en la nueva lucha que iba a empezarse.

Con esos salteños que me acompañaron combatí en Ituzaingo, adquiriendo ellos un nuevo y poderoso título la gratitud de la patria y a mi propia estimación: digo mi estimación porque fueron siempre mis fieles compañeros, obedientes a mi voz y porque me dispensaron siempre confianza que nunca se desmintió ${ }^{24}$.

Nótese la desmesura de la tarea cumplida, para gente que ya hacía más de una década que estaba peleando, sin remuneración y proveyendo su sustento y sus necesidades como caballos, armas, etc. Y si bien lograron, en general, el respeto de sus superiores, como ya señalamos, las miradas sobre las milicias y sus formas de organizarse y luchar era muy despreciativa. El propio Paz contaba en sus memorias cómo reprendía a su tropa diciéndoles que no eran "gauchos para gritar" o planteando que en el combate de Puesto del Marqués el desorden era tal que "parecía más una toldería de salvajes que un campo militar"25.

La resistencia que van a generar estas levas y reclutamientos forzosos, no eran temores injustificados. Los iniciales despuntes de un estado nacional prologaban con tareas desmesuradas las inmensas cargas que posteriormente se descargarían sobre los sectores populares. La necesidad de mantener una fuerza militar que dirimiera tanto conflictos fronterizos como las disputas internas, a la vez que controlar a los sectores populares, se reflejó en la creación de cuerpos militares con recortes importantes a las prerrogativas y la autonomía de las fuerzas milicianas. Así, un mes antes, en Jujuy se había formado el Regimiento de Caballe-

24 José María Paz, Memorias Póstumas. (Buenos Aires: Imprenta de la Revista,1855) Tomo 1, 68. El combate de Puesto del Marqués fue un enfrentamiento contra tropa realista, en la Puna, el 14 de abril de 1815. Allí intervienen en forma conjunta el Ejército del Norte, bajo el mando de José Rondeau y los escuadrones gauchos, con Martín Miguel de Güemes a la cabeza. José María Paz, Memorias Póstumas, 207 y 209. 
ría de Línea, separado 148 hombres de los Escuadrones de Yavi, Santa Victoria, Iruya, Humahuaca y Tilcara ${ }^{26}$.

Por lo tanto, claramente los gauchos de Caspalá tenían sobrados argumentos para resistirse, si bien la orden puntual estaba orientada a la custodia de la tropa de Tarija, lo cual como veremos en seguida, resultaba injusto a los sublevados.

\section{Los SENDEROS DE LO POLÍtico (I): DE GAUCHOS A MOTINISTAS}

Terminado el enfrentamiento con los españoles, y con las perspectivas planteadas en el punto anterior, no resulta extemporáneo que los gauchos de Caspalá se preguntaran: “...y que por qué iban a escoltar a otros hombres como ellos aunque viniesen de Tarija por disposición del Gobierno, que ya no servían a nadie que demasiado habían servido antes..." 27 .

Aún justificada, esta interrogación no debería naturalizarse a riesgo de pasar por alto una clara inflexión en la conciencia política de estos sujetos: de una acción defensiva, colectiva, sí, pero de salvaguarda personal, a partir de una acción por la negativa, se pasa a la afirmación de un colectivo mayor y más abstracto.

Repasemos la dinámica de la situación: inicialmente todos acusados hablan a una voz, sin argumentos precisos y quien eventualmente se convierte en una voz particular, lo hace como un alarde de bravuconada personal:

"no podía salir de allí porque no tenía caballo" y cuando lo reconvienen "que cómo tenía caballo para hacer sus diligencias y no lo tenía para el acto de servicio..." contestó que "no sabía por qué no tenía caballo"28.

Como ocurre frecuentemente, la coagulación de una conciencia política aparece como producto del diálogo que se produce, en los hechos,

26 1826, AHPJ, Gobierno, Fondo Archivo, caja 2.

27 1826, AHPJ, Gobierno, Fondo Archivo, caja 2.

28 1826, AHPJ, Fondo Archivo. 
entre las reacciones del poder frente a su impugnación. Así, el discurso de los gauchos se irá definiendo cada vez más en el plano político, contrastando fuertemente con una autoridad que parece demorar en creer lo que está ocurriendo y por ende en reaccionar.

Efectivamente, la autoridad directa, el Comandante Pastor, lejos de alarmarse, inicialmente parece tener dos inquietudes: por un lado, si los oficiales del escuadrón participaron del motín y si hay un cabecilla notorio. En cuanto a la primera cuestión, es comprensible, la jerarquía castrense no era el fuerte de la organización miliciana, eran permanentes los cuestionamientos individuales o colectivos de la oficialidad a autoridades, órdenes, etc ${ }^{29}$.

La escasez de soldados en general y de cuadros jerárquicos en particular, permitía cierta distribución del poder también en el interior del arma y no sólo hacia los civiles, como el fuero militar lo permitía. La reacción de las autoridades frente al pronunciamiento, deja en evidencia lo que sería el repertorio habitual de negociaciones que se abrían ante estos hechos cotidianos de insubordinación: se interroga sobre motivaciones, se advierte sobre posibles castigos, y hasta se les propone que elijan con quién negociar: “...que le avisasen si querían que fuese otro oficial a traerlos..."'"30, mostrando el reconocimiento de los liderazgos personales. Fuera de estos ademanes - podríamos decir recurrentes, no parecería haber muchas más ideas, por lo que se vuelve a pedir a los superiores órdenes por escrito para afirmar la autoridad, "les hizo saber la orden que llevaba en la que los decía su comandante que tratasen de obedecer sus órdenes que si no lo verificaban en aquella segunda vez serían castigados con el rigor de la ley..."31

Nótese en estos documentos las atenuaciones del lenguaje y el paternalismo con la que los superiores se dirigen a la tropa: que tratasen de obedecer, y que si no lo hacían en la segunda vez (sic) serían castigados. Es frente a esta amenaza que surge la ampliación de la conciencia que se

31 1826, AHPJ, Fondo Archivo. 
traduce en la construcción de un amplio colectivo gaucho que abarcaba a los reclutas de Tarija, pero también a eventuales contingentes que subirían de Jujuy para reprimir el alzamiento:

“...contestaron todos a un tiempo...que si el comandante los amenazaba diciéndoles vendría tropa de Jujuy a prenderlos nada se les daba, que estaban seguros que aunque tuviese efecto nada les habían de hacer porque eran sus hermanos y últimamente que nadie los sacaba de sus casas" 32 .

Un mes más tarde, este embrión de conciencia se había potenciado en acción política: con un líder ya definido, el Cabo Lorenzo Apasa, y una coordinación con todos los escuadrones desde Volcán hasta Antumpa y el Curato de Humahuaca, Iruya, Valle Grande y San Andrés. Posteriormente intentan -y al parecer, durante un tiempo logran- sumar a las comunidades de Casabindo y Cochinoca.

Pero no sólo tienen dirigentes, también tienen un programa propio: se propugnaba la unidad para evitar la leva y para no tener que intervenir en nuevos enfrentamientos y nuevas guerras.

Tres principios parecen alentarlos: unidad/confraternidad; libertad y sosiego como recompensa por sus aportes en la guerra. La reiteración de los tópicos principales y la unanimidad del discurso en las nutridas declaraciones que componen las sumarias del caso, evidencian un profundo consenso generado tanto por la prolongada experiencia compartida, como por seguramente, extensas deliberaciones.

Los protagonistas utilizan un lenguaje utópico, con palabras como "hermandad", "unidad", "vivir sosegados trabajando" y hasta con un tono sacrificial de "resistir hasta la muerte". Describen sus servicios durante la guerra como un "trabajo", el cual merece una recompensa, más aún cuando fue realizado a propia costa y sin salario; esa recompensa es apelada como "sosiego" y más claramente como "libertad". En cuanto a la acepción de un vocablo tan usado, me remito a las palabras de Sara 
Mata para los esclavos que integraban los escuadrones gauchos de Salta; los esclavos luchaban por una patria

“...concebida como un orden social en el cual la libertad no era entendida en los mismos términos en que la planteaba la dirigencia revolucionaria, es decir no tan solo la libertad soberana y en unión con ella libertad cívica, o sea libertad de gobernar y de participar del gobierno, que en estos momentos significaba la ruptura de la relación colonial, sino que la libertad reclamada por los esclavos estaría vinculada fundamentalmente a la libertad personal, es decir la capacidad de acción y de decisión sin depender de otros, derecho del cual debían gozar todos los hermanos, incluidos los esclavos..."33.

En el ejercicio de su libertad, los gauchos de Caspalá durante el conflicto, permanecerán en sus casas trabajando y se reunirán para defenderse de las partidas, elegirán a sus dirigentes y les asignarán grados militares en abierto desafío a las autoridades.

Así lo planteaban los protagonistas:

"estamos a una voz a la unión y libertad": "ya nosotros ya no queremos meternos en guerras como es en alzar armas".

“...las miras que tenían eran las de vivir descansados y no perjudicar a nadie a menos que nos los persiguiesen porque sus jefes les habían asegurado antes que en recompensa de su trabajo en tiempo que invadían esta provincia los españoles habían de trabajar con constancia con sus personas, con sus cabalgaduras y alimentándose a su costa y mención y a más de esto que habían auxiliado con sus intereses y no habían visto un medio cuyos documentos de constancia los ha recogido el Coronel Dn. Francisco Pastor..."

33 Sara Emilia Mata, "La herencia de la guerra: Salta (Argentina) 1821-1831", Nuevo Mundo Mundos Nuevos (2012). DOI: https://doi.org/10.4000/nuevomundo.63221 
“...que las miras que había eran de resistir hasta morir a cualquier partida que les fuese a traer y que si no iban dichas partidas no habría nada y vivirían sosegados trabajando..."34

A diferencia del programa insurreccional salteño, en Caspalá no aparece con claridad la reivindicación por la tierra y los arrendamientos. El único que menciona que los amotinados se negaban a pagar arriendo es el terrateniente Mauricio de Goyechea, quien precisamente fue a Caspalá a cobrarlos.

Casualmente sus dependientes son los principales dirigentes del motín, quienes declaran haberse reunido con él para averiguar sus intenciones.

Mientras Goyechea declara que fueron a amenazarlo, los gauchos dirán que fueron a "saludar a su patrón” y a decirle: “... que estamos con este trabajo no pudimos pagarle arriendos porque estamos sin plata y después de salir de este trabajo le pagaremos ..."35.

Avanzadas las acciones de resistencia de los "tumultuarios", se despliega la represión: los comandantes solicitan "se traslade una partida siquiera de 25 hombres bien armada al mando de un oficial de carácter que sepa desempeñar la comisión para evitar trastornos que pudieran sobrevenirnos en esta quebrada..."36.

Resulta interesante advertir que se confía más en el oficial de carácter -que en este caso será Manuel Álvarez Prado- que en una tropa numerosa, destacando una vez más la importancia del liderazgo personal por sobre las jerarquías establecidas. Notoriamente también confía el propio Álvarez Prado quien a los pocos días informa al Teniente de Gobernador -a la sazón Sánchez de Bustamante- que los partidos de Caspalá y Lomlonzo 
"se mantendrán en quietud respetando las autoridades y observando el orden por quedar estos bien rencargados por mi..." 37 .

La confianza en la disolución del motín deviene de haber tomado prisioneros al padre y a todos los hermanos de Apasa -el principal dirigente- y a otro conjunto de milicianos, en un total de 11, incluyendo al Sargento del Escuadrón de Iruya -información que de paso nos permite advertir la extensión del conflicto.

En los interrogatorios e informes se podrá apreciar que una parte de estos prisioneros no han tenido intervención en los hechos, sino que son tomados como rehenes para procurar que sus parientes se entreguen. Este hecho nos permite advertir tanto una forma muy particular del ejercicio de la justicia, como su eficacia, ya que por ejemplo, permite apresar a José Olarte, uno de los cabecillas, quien se presenta voluntariamente para liberar a su padre. Dicho Olarte ha adquirido el rango de "cabo" por elección de sus compañeros. El tema de las tramas familiares ha sido abordado de manera central para la región y estos avances nos impulsan a su planteamiento en particular para los escuadrones gauchos, lo que será tratado en nuevos avances de esta investigación ${ }^{38}$.

Combinada con esta fuerte acción represiva, se retoman las acciones consensuales y paternalistas, se comisiona al Capitán Burgos y al Abanderado Nicolás Cruz "con orden de que en el momento de encontrarlos los atraviesen invitándoles a la paz...” “... amonestándolos no vuelvan a incurrir en semejantes atentados que si esta se los había disimulado en otra serian castigados con el rigor de la ley, lo que me prometieron todos..." 39 . jujeño del XIX”, Surandino Monográfico No. 1 (2016) http://revistascientificas.filo.uba.ar/index. php/surandino/article/view/3501 


\section{Los SENDEROS DE LO POLÍtico (II): DE MOTINISTAS A REVOLUCIONARIOS}

Desmintiendo las expectativas optimistas de los oficiales, entre Diciembre de 1826 y Enero de 1827, la situación volverá a cambiar de calidad. No sólo la situación no se ha sosegado, sino que se levanta el Escuadrón de Iruya, se definirán dos nuevos liderazgos que acompañarán a Apasa entre quienes no habían participado inicialmente: Martín Condorí y el Abanderado Nicolás Cruz, al cual habíamos conocido poco antes, como uno de los encargados de de disolver el conflicto, y que ha sido designado Comandante por sus compañeros.

Pero el cambio fundamental será el paso de la resistencia al ataque sin que nuestra investigación nos permita dar cuenta todavía, de las razones de este cambio. Daría la impresión de que los levantamientos en Tarija, en contra del Gobierno de Salta y su incorporación a la República de Bolivia, así como la acumulación de tropas en la frontera, abrieron un horizonte de expectativas para los rebeldes, que además resultaban viables.

Estas expectativas los terminaron alejando definitivamente de su tan ansiada vida de sosiego.

Así, el designado popularmente Comandante Nicolás Cruz le escribió al Comandante del Escuadrón de San Andrés un documento por demás expresivo: ${ }^{40}$

“Apreciadísimo Señor Comandante Don Pedro Velasques esta le halle con entera salud. Por esta se ofrece dar de saber gobierno de Colombia$\mathrm{no}^{41}$ viene solicitando compostura buenamente y no pretende guerras sino libertar aquí estamos perseguidos como a enemigo siendo unos hermanos y compañeros que defendíamos una sola causa y esto ha extrañado el Señor Gobernador colombiano y libertador y por tanto

40 Recuérdese lo que señalamos en la introducción, acerca de esta población subalterna que sabe escribir.

41 Entendemos que es la forma de nombrar a Antonio José de Sucre, Presidente de la República de Bolivia entre 1825 y 1828. 
mi ha pasado una Proclama ya te habrás impuesto en ello en esta virtud le pido favor a Usted que me protejas como a su hermano fiel y por tanto te participará su gobierno ya seguro que mi ha de persiguir estas dos comandancias porque defiendo una sola causa de dar, no me hey dar, por esto quero su contes para mi gobierno y mande a este su afmo fiel QSMB dios guie a Usted muchos años". Coloraos, 7 de Enero de $1827^{\prime \prime 4}$.

Los informes declaran que Apasa ya instituido como caudillo, se había entrevistado en Tarija con Eustaquio -Moto- Méndez ${ }^{43}$ quien en ese preciso momento estaba liderando un exitoso movimiento para independizar la Tenencia de Tarija (hasta ese momento parte de la provincia de Salta) e integrarla a Bolivia con el auxilio de las tropas colombianas ${ }^{44}$.

Si bien este asunto tardó un tiempo en resolverse, parecería que los amotinados quedaron incluidos en los hechos, dentro de una estrategia para fijar la frontera de Bolivia en Humahuaca. Esto implicaría un salto gigantesco en la calidad de la politización, integrándose -podríamos decir- a un proyecto "nacional".

Sin embargo, la persistencia de los gauchos rebeldes en sus propios principios discursivos, traduciría más bien una búsqueda de salida y apoyo para su propio proyecto, que la enajenación en un proyecto dominante. Esto era posible, sin duda, por lo inaccesible de su hábitat. Sin embargo, daría la impresión de que ya sea por sus alianzas con Tarija o con sus "hermanos", se ven impulsados a abandonar su refugio.

El 31 Enero de 1827 los amotinados están en Yavi. Así lo relata el Coronel Juan Antonio Ruiz, quien realiza una descripción pormenorizada de una incursión del dirigente Lorenzo Apasa sobre el pueblo fronterizo. Ruiz señala que la incursión cuenta con el apoyo del Escuadrón de

42 "Carta de Nicolás Cruz Archivo", 1827, AHPJ.

43 Eustaquio Mendez Arenas, caudillo de Tarija, de importante y polémica actuación en las guerras de Independencia y que una vez proclamada la República de Bolivia continuó combatiendo impulsando diversas alternativas, pero fundamentalmente en oposición a la permanencia de Tarija como parte de la Provincia de Salta. Muere en 1849.

44 "Disposición del Congreso General de las Provincias Unidas del Río de la Plata (Buenos Aires, 13 de septiembre de 1825)" en Historia de Tarija, dir. Cristina Minutolo, XII. 
Yavi $^{45}$, amotinado desde principios de ese mes. Ruiz destaca su propio mérito, señalando que para defender las armas escondidas en su domicilio, sólo contaba con sus hermanos y 5 soldados. Informa que con esta fuerza logró matar a 12 insurrectos y correrlos hasta Cangrejillos. Pero con esta acción sólo logran aplazar lo que se teme sea un ataque mayor sobre toda la Puna en alianza con Casabindo y Cochinoca y una entrada definitiva sobre Humahuaca, que finalmente no se realiza.

Frente a semejante amenaza se piden auxilios al Gobierno de Salta, quien se encuentra sumido en sus propios enfrentamientos armados, con la amenaza de Facundo Quiroga entrando en Tucumán, el levantamiento de Francisco Gorriti en Rosario de la Frontera y las movilizaciones de los escuadrones gauchos sobre la ciudad ${ }^{46}$.

El Gobernador Arenales le plantea a Sanchez de Bustamante que no puede disponer ni de una sola arma para defender la Puna:

“... Vuestra Señoría no ignora que esta ciudad se halla en cierto modo circunvalada de los enemigos que habían creído ser capaces de forzar estas trincheras,... Vuestra Señoría debe hacerse cargo que defendido este pueblo se defiende el de Jujuy y si este desgraciadamente sucumbe, Jujuy en caso tal no podrá contrarrestar la fuerza que habrían llegado a adquirir los revolucionarios..." ${ }^{47}$.

A partir de allí los enfrentamientos serán periódicos y las luchas se irán engarzando unas con otras.

\section{Las Marcas discursivas del paisaje}

Adaptarse para sobrevivir en una región con grandes dificultades implica partir de valores que no son los de las mayorías. Podríamos esta-

\footnotetext{
45 No tenemos otras referencias sobre la existencia de un escuadrón en Yavi. Supuestamente los gauchos de la Puna se disolvieron como organización con la derrota del Fernando Campero y el Regimiento del Peru. Sin embargo, esta referencia nos impulsa a indagar sobre el tema.

46 Sara Mata, La herencia de la guerra.

47 1827, AHPJ, Fondo Archivo.
} 
blecer relaciones significativas entre las "ventajas" del aislamiento y el pronunciamiento que realizan los gauchos en el año 1826.

Su demanda, y su práctica durante gran parte del tiempo que duró el levantamiento, de trabajar sosegadamente, entre hermanos, etc., se acomoda mejor a aquellos parajes, que en los disputados territorios quebradeños. Pero por supuesto que no era una condición utópica ni idílica, sino simplemente que el hecho de cierto aislamiento generaba expectativas y proyectos.

Conocemos las dificultades y beneficios que brindó la región para el desarrollo de guerrillas, aunque el papel jugado por los escuadrones de los valles se diluye frecuentemente en el servicio de los de Humahuaca, en general, y resulta muy dificultoso observar su actuación específica.

Los Valles son señalados como lugares de paso y poco más. Sin embargo, la historia oral recoge relatos de emboscadas y ataques de los ejércitos realistas, los cuales, por su parte, no tenían otra opción que descolgar una columna secundaria por allí, en sus avances hacia San Salvador de Jujuy.

La tarea miliciana en esas condiciones debió haber sido tan propicia como sacrificada, a la vez que sostenida por la fuerza de estar defendiendo el espacio propio: "dice que el Escuadrón se hallaba en el Valle de Caspalá por ser naturales de allí los soldados de ella"48.

Pero no resultó llamativo que el discurso viniera a enfatizar las características que hacían de estas tierras la fortaleza de los gauchos y la debilidad de sus enemigos. Así, encontramos marcas de subjetividad que hacen la referencia a un espacio peligroso, oscuro y amenazante.

Los protagonistas utilizan la imagen de "salir" para indicar el desplazamiento que deben hacer los gauchos para cumplir las órdenes. Los comandantes tuvieron que soportar la condición privativa que impusieron los soldados de la Independencia de regresar a sus casas después de

48 1826, AHPJ, Fondo Archivo. 
cumplir con el servicio, como préstamo de formas indígenas o al menos populares de hacer la guerra ${ }^{49}$.

Ausentarse de sus casas era tanto posible como - si se hacía en determinados tiempos- inviable en tiempos prolongados, era imposible para hombres $-\mathrm{y}$ eventualmente, mujeres- con los ritmos particulares de las tareas agrícola-ganaderas.

Podrían apartarse con la condición de acudir en el momento indicado. Sin embargo, para los hombres de los valles, la acción de acudir al llamado de sus superiores tenía tintes particulares. Entendemos que la idea de "salir" hacia Humahuaca para cumplir con su deber y no subir o bajar, que es la manera en que se designan habitualmente los traslados en la región, les sonaba más amenazante.

Los soldados deben "salir" y esa misma acción es lo que los expone a un mundo extraño, con reglas diferentes y donde la ventaja de su conocimiento de lo desconocido se desvanece; donde el misterio del territorio, del que ellos tienen la llave, ya no los protege. Por eso los partes militares señalan que los gauchos están “...resintiéndose a no querer salir ni pasar un palmo de tierra de aquella..."

En los partes militares sobre la represión del conflicto, las noches son "terribles" y se mencionan varias escenas donde los amotinados aparecen de madrugada, mostrándolos como más amenazantes: "A la madrugada se avistaron 80 hombres en el Abra de Tejada, que deben ser revolucionarios" $"$.

Los rebeldes rodean a las tropas, los convencen de acompañarlos y “... reunidos todos con la gavilla del criminal Martin Condori ganaron los cerros de la Cordillera proiegtando (protestando) avanzar este pueblo" ${ }^{2}$.

49 Raquel Gil Montero, "Las Guerras de Independencia en los Andes Meridionales", Memoria Americana No. 14 (2006): 89-117.

50 1827, AHPJ, Fondo Archivo.

51 1827, AHPJ, Fondo Archivo.

52 1827, AHPJ, Fondo Archivo. 
Su territorio sí los protege. Así se señala que cuando apresan a quienes van a reprimirlos, los llevan a quebradas ocultas o por caminos extraviados; obligan a multiplicar los refuerzos, de los 25 hombres que se organizan inicialmente para reprimirlos, hasta 150, con dos oficiales, ya que "...la distancia de la serranía que nos separaba y la inutilidad de nuestras cabalgaduras nos privó el que lo hubiésemos hecho en un solo punto..." 53 .

En los relatos podemos ver cómo se despliegan tres dimensiones del espacio: a la primera dimensión, el espacio propio, el refugio se sumarán en el proceso de politización, el de las poblaciones cercanas y la hermandad, que demarca toda una región insurrecta: desde Volcán hasta Antumpa y todo lo que pertence al curato de Humaguaca y la gente de Iruya San Andrés y Santa Cruz Posteriormente se sumarán aliados en Yavi, Casabindo, Cochinoca; finalmente la protección del líder tarijeño Moto Mendez y como una figura espectral el "Gobernador Colombiano", es decir Sucre, a quien nunca se lo llama por su nombre.

Como se notará la cercanía no es un problema geográfico, ya que el motín expande su alcance hasta un área extensa; sino que se trata de una cercanía socio-cultural, de acceso, de confianza. Es un espacio por el que van y vienen noticias, informes, cartas, acuerdos, sostén. Es un espacio amplio, flexible y comunicado.

Superpuesto geográficamente al segundo el espacio, está el espacio del "salir", un espacio con el que confrontan, en el cual han prestado servicio, han "trabajado" como ellos dicen, donde nunca se sintieron cómodos y que no sienten como propio. Es un espacio donde son defraudados, manipulados. Es el espacio donde son subordinados y los gauchos lo saben.

Es cierto que en la relación con sus superiores no aparece maltrato, al contrario, los jefes militares más cercanos se notan preocupados por no perder su ascendiente sobre la tropa, piden favores personales, procu-

53 1827, AHPJ, Fondo Archivo. 
ran morigerar las penas y aislar discursivamente a los dirigentes de una masa que necesitan para guerrear y para trabajar.

Si el maltrato material está morigerado, aparece como jerarquía, autoridad paternalista. El discurso es el de un padre reprendiendo a su pequeño para que no cometa travesuras. El problema es que en esta historia, la autoridad quiere imponer la vida y la muerte.

Pero los rebeldes no se dejan engañar, desnudan la falsedad del discurso paternalista y erigen sus nuevos líderes.

El Capitán del Escuadrón, quien vive en Caspalá, es decir, que es el más cercano de los jefes, se dirige a una reunión de 50 hombres en medio del conflicto "para aconsejarlos que sean obedientes y subordinados y habiéndolo verificado dicho señor le contestaron todos a una voz que no lo necesitaban para nada supuesto que no quería ponerse a la cabeza de ellos" $" 54$.

\section{ConClusiones}

Este trabajo, que sólo trata de un pequeño ejemplo, es parte de preguntas que se han planteado ya, pero que merecen ser profundizadas, sobre todo para Jujuy: ¿quiénes fueron los gauchos jujeños? ¿por qué pelearon? ¿qué lograron? ¿qué perdieron? ¿qué pasó con estos sujetos al finalizar la guerra?

La primera respuesta a estas preguntas es recordar que el colectivo "gaucho" es en primer lugar un apelativo de la época, que designa en nuestro territorio a los miembros de escuadrones conformados por Martín Miguel de Güemes para organizar, centralizar, potenciar y dirigir las diversas expresiones de lucha que están dispuestos a llevar adelante las clases populares rurales contra los españoles. Pero estas clases son diversas y si bien comparten intereses y móviles de base las diferencias son considerables.

54 "Declaración del gaucho José Benito Gutiérrez", 1826, AHPJ, Fondo Archivo. 
En cuanto a los protagonistas de nuestra historia, podríamos afirmar que la reivindicación de vida y trabajo sosegados es un programa básico de toda comunidad campesina, en particular las que como ésta, se encuentran más aisladas. Es interesante registrar, que a diferencia de sus congéneres de Lerma, no tienen una demanda clara por la tierra, quizá porque el conflicto en los valles fuera más atenuado. Por lo pronto parecería ser que estos sujetos tenían un programa propio en la guerra de Independencia, sencillo, pero propio.

Mientras ese programa parecía el programa común de la Revolución, era un programa tácito e indefinido. Este programa toma discurso y encarna en dirigentes propios cuando las milicias sienten que son abandonados en sus demandas, son confrontados por los jefes en los que se referenciaban y decían protegerlos, además de violentados en su voluntad y castigados por su resistencia a obedecer.

Entonces elijen continuar la pelea, pero en un terreno que elije, una pelea por su propio programa, un programa que los empuja una vez más a la guerra, aunque tenga un fuerte clivaje en la paz. Por el contrario, ya no están dispuestos a pelear por programas abstractos como la "defensa de la patria", ya que entienden que ese discurso los obliga a enfrentarse con "hermanos".

Así los documentos evidencian una conciencia política autónoma y definida: un mundo de pertenencias y relaciones: los amotinados dividirán el mundo entre el espacio de los "hermanos" y el de quienes debiendo protegerlos, los persiguen injustamente. Y esta división es tan profunda, que pone en cuestión una frontera que se está formando y que desvela a las autoridades: la frontera con la nueva República de Bolivia.

Por lo pronto, la concepción, uso de territorio, pero más claramente su ser en el espacio y el paisaje, es otro punto clave en el conocimiento de estos sujetos. Y es en este sentido que pensamos que el fin de la Guerra de Independencia generó otras fronteras, algunas más ostensibles como la ya señalada con Bolivia, pero otras que también se dirimieron 
en el mismo y otros terrenos: fronteras sociales y políticas, que durante mucho tiempo las fanfarrias conmemorativas ocultaron como la tierrita bajo la alfombra, y con ella, las luchas, sueños y decires de un conjunto de hombres que construyeron aquello que se conmemora, pero que son los que no reciben la tarjeta de invitación en el momento del re-conocimiento, es decir, no de la loa abstracta, sino de la legitimidad como sujeto político, reclamante de derechos que aún hoy no son reconocidos.

\section{BibLIOGRAFÍA}

\section{Fuentes Primarias}

\section{Fuentes de Archivo}

Archivo General de la Nación (AGN), Buenos Aires - Argentina. Sala X. Archivo Histórico de la Provincia de Jujuy (AHPJ), Jujuy - Argentina, Fondo Archivo.

\section{Fuentes Secundarias}

Belli , Elena "Algunas implicancias de las políticas de ajuste económico y modernización en Valle Grande Provincia de Jujuy" tesis doctorado en Antropología, Universidad de Buenos Aires, 2004 URI:http:/ / repositorio.filo.uba.ar/handle/ filodigital/1253

Bidondo, Emilio A. Coronel. Contribución al Estudio de la Guerra de la Independencia en la Frontera Norte. El Aporte Jujeño, Buenos Aires: Círculo Militar, 1968.

Conti. Viviana. "Jujuy 1810". En Jujuy de la Revolución de Mayo a nuestros días, editado por. Marcelo Lagos y Viviana Conti , San Salvador de Jujuy: Ediunju, 2010.

Ferreiro, Juan Pablo y Federico Fernández, "Vino nuevo en viejos odres. Perspectiva microestructural, redes y fuentes tradicionales", Econtros Bibli; Vol. 19 (2014): 157-184 http://hdl.handle. net/11336/36201.

"Disposición del Congreso General de las Provincias Unidas del Río de la Plata (Buenos Aires, 13 de septiembre de 1825)" en Historia de 
Tarija, dir. Cristina Minutolo de Orsi (Corpus Documental). Tarija: Universidad Autónoma "Juan Misael Saracho", 1987, Tomo III, 187-189.

Ferreiro, Juan Pablo, "De barro somos... Ciclos familiares y genealogía en el poblamiento del oriente jujeño del XIX", Surandino Monográfico No 1(2016) http:// revistascientificas.filo.uba.ar/index. $\mathrm{php} /$ surandino/article/view/3501

Gil Montero. Raquel, "Las Guerras de Independencia en los Andes Meridionales", Memoria Americana 14 (2006).

Gil Montero, Raquel, La construcción de Argentina y Bolivia en los Andes Meridionales. Población, tierras y ambiente en el siglo XIX, Buenos Aires: Prometeo, 2008.

Mata, Sara E, "Conflicto político y propiedad de la tierra. Salta 18101830”, VIII Jornadas Interdisciplinarias de Estudios Agrarios y Agroindustriales (Buenos Aires: Centro Interdisciplinario de Estudios Agrarios, 2013. http://www.ciea.com.ar/jornadas-anteriores / viii-jornadas-interdisciplinarias-de-estudios-agrarios-y-agroindustriales-2013/12/4/2019

Mata, Sara E, "Conflicto y violencia en tiempos de crisis. Salta (Argentina) en las primeras décadas del siglo XIX", Revista Secuencia 90 (2014) 2.

Mata, Sara E, "La herencia de la guerra: Salta (Argentina) 1821-1831", Nuevo Mundo Mundos Nuevos (2012). DOI: https://doi. org/10.4000/nuevomundo.63221

Mata, Sara E, “Tierra y revolución. La campaña salteña en las primeras décadas del siglo XIX” Mundo Agrario Vol 17 No. 35 (2016)

Mata, Sara E. Los gauchos de Güemes. Guerras de Independencia y conflicto social. Buenos Aires: Sudamericana, 2008

"Oficio de Güemes al Director Pueyrredón (Salta, 17 de octubre de 1816)", en Güemes documentado, ed. Luis Güemes. Buenos Aries: Editorial Plus Ultras, 1979, Tomo 4, 69-70.

Paz , Gustavo, "El orden es el desorden" Guerra y movilización campesina en la campaña de Jujuy, 1815-1821”, en Desafíos al Orden. Política y sociedades rurales durante la Revolución de Independencia, editado por. Raúl Fradkin y Jorge Gelman, Rosario: Prohistoria, 2008. 
Paz, Gustavo, "Province and Nation in Northern Argentina. Peasants, Elite, and the State, 1780-1880", tesis de doctorado en Historia, Universidad Emory, 1999

Paz, Gustavo, "Reordenando la campaña: la restauración del orden en Salta y Jujuy, 1822-1825”, en ¿Y el pueblo dónde está? Contribuciones para una historia popular de la Revolución de Independencia en el Río de la Plata, editado por Raúl Fradkin, Buenos Aires: Prometeo. 2015, 194.

Paz, José María, Memorias Póstumas. Buenos Aires: Imprenta de la Revista,1855.

Sica, Gabriela, "Paisajes agrarios coloniales en la Quebrada de Humahuaca. Tierras privadas, tierras comunales. Siglos XVI-XVIII", En: Quebrada de Humahuaca. Estudios Históricos y Antropológicos en torno a las formas de propiedad, editado por Ana Teruel y Cecilia Fandos, San Salvador de Jujuy: Ediunju. 2014.

Teruel, Ana y Omar Jerez comps. Pasado y presente de un mundo postergado. San Salvador de Jujuy: Unidad de Investigación en Historia Regional-UNJu (1998).

Para citar este artículo: Gresores, Gabriela. "Organización y programa político de los "gauchos" de Jujuy a fines de la Guerra de Independencia”, Historia Caribe Vol. XV No. 36 (Enero-Junio 2020): 73-103 DOI: http:/ /dx.doi.org/10.15648/hc.36.2020.5 